\title{
Effect of sutureless implantation of the Perceval $S$ aortic valve bioprosthesis on intraoperative and early postoperative outcomes
}

\author{
Willem Flameng, MD, PhD, ${ }^{\mathrm{a}}$ Marie-Christine Herregods, MD, PhD, ${ }^{\mathrm{b}}$ Hadewich Hermans, $\mathrm{MD},{ }^{\mathrm{b}}$ Gerry Van \\ der Mieren, MD, ${ }^{\mathrm{a}}$ Monique Vercalsteren, RN, ${ }^{\mathrm{a}}$ Gert Poortmans, $\mathrm{MD},{ }^{\mathrm{c}}$ Jan Van Hemelrijck, MD, PhD, ${ }^{\mathrm{c}}$ and \\ Bart Meuris, $\mathrm{MD}, \mathrm{PhD}^{\mathrm{a}}$
}

\begin{abstract}
Objective: Prolonged aortic crossclamping can increase mortality and morbidity after aortic valve replacement in elderly and high-risk patients. Sutureless implantation of the prosthesis has the potential to shorten aortic crossclamp time.
\end{abstract}

Methods: The Perceval S valve (Sorin Biomedica Cardio Srl, Sallugia, Italy), a sutureless implantable aortic
bioprosthesis, was used in 32 patients (median age, 78 years; median logistic euroSCORE, 9.99) requiring aortic
valve replacement with or without concomitant coronary artery bypass grafting. Hemodynamic parameters and
clinical outcome were obtained at discharge, at 6 months, and up to 1 year postoperatively.

Results: Aortic crossclamp time needed for aortic valve replacement was $18 \pm 6$ minutes. Hemodynamics at discharge showed good function of all Perceval S valves with low transvalvular pressure gradients (mean, $12 \pm 5 \mathrm{~mm}$ $\mathrm{Hg}$ and peak, $23 \pm 9 \mathrm{~mm} \mathrm{Hg}$ ) and low incidence of paravalvular or valvular leakage. Operative mortality was $0 \%$. Follow-up at 1 year showed 3 non-valve-related deaths. Survivors showed good clinical outcome and stable hemodynamic function of the valve prosthesis, except for 1 patient in whom endocarditis developed. Despite a moderate decrease in platelet counts persisting up to 12 months, freedom of bleeding and thromboembolic events was $100 \%$.

Conclusions: It is possible to implant a well-functioning sutureless stent-mounted valve in the aortic position in less than 20 minutes of aortic crossclamping. This is associated with excellent early clinical and hemodynamic outcome in high-risk patients. Moderate changes in hematologic parameters persisted but were not related to clinical events. (J Thorac Cardiovasc Surg 2011;142:1453-7)

Video clip is available online.

In Europe, it was recently suggested that approximately one third of patients aged more than 75 years with valvular heart disease do not undergo surgical aortic valve replacement (AVR) because of risks arising from age and comorbidities. ${ }^{1}$ This observation stimulated the development of lessinvasive transcatheter aortic valve (TAV) procedures. It was believed that TAV procedures would be associated with lower mortality and morbidity compared with surgical AVR in elderly patients. However, TAV procedures have the potential for serious complications related to the transcatheter place-

\footnotetext{
From Cardiac Surgery, ${ }^{\mathrm{a}}$ Cardiology, ${ }^{\mathrm{b}}$ and Cardiovascular Anesthesiology, ${ }^{\mathrm{c}}$ Department of Cardiovascular Diseases, Katholieke Universiteit Leuven, Leuven, Belgium.

Disclosures: The valves used in this study were donated to the study by Sorin Biomedica Cardio, Italy. The authors had full control of the design of the study, methods used, outcome parameters, analysis of data, and production of the article.

Received for publication Oct 12, 2010; revisions received Feb 7, 2011; accepted for publication Feb 18, 2011; available ahead of print April 8, 2011.

Address for reprints: Willem Flameng, MD, PhD, Cardiac Surgery, University Clinic Gasthuisberg, Herestraat 49, B-3000 Leuven (E-mail: willem.flameng@med. kuleuven.ac.be).

$0022-5223 / \$ 36.00$

Copyright (C) 2011 by The American Association for Thoracic Surgery

doi:10.1016/j.jtcvs.2011.02.021
}

ment itself, such as vascular complications, aortic dissection/perforation, stroke, myocardial infarction, and major ventricular tachyarrhythmia. ${ }^{1,2}$ Overall 30-day major adverse cardiovascular and cerebral events range from $3 \%$ to $35 \% .^{1}$ On the other hand, once in place, the stentmounted valves function well with low transvalvular gradients. Still, the fact that the TAV procedure does not allow the removal of the stenosed native valve raises questions on the stability of valve function over time. Also, the relationship between the degree of calcification and the high incidence of paravalvular leakage as it is observed after TAV placement remains to be elucidated. These findings stimulated the interest in an alternative development, that is, a collapsible, stent-mounted aortic valve prosthesis that can be placed in a sutureless fashion with a conventional surgical technique. ${ }^{3}$ Sutureless implantation of heart valves has a significant advantage over the classic technique of suturing the valve in place, because it shortens the necessary aortic crossclamp time and therefore also the myocardial ischemia time. This technology includes a classic extracorporeal circulation, crossclamping of the aorta and an aortotomy, allowing complete removal of the diseased native valve. The Perceval $\mathrm{S}$ (Sorin Biomedica Cardio Srl, Sallugia, Italy) bioprosthesis is such a sutureless aortic valve constructed from bovine pericardium and mounted in a Nitinol stent. ${ }^{3}$ This stent-mounted valve can be compressed and positioned in a transluminal valve delivery system. The valve can be delivered through 


\section{Abbreviations and Acronyms \\ AVR = aortic valve replacement \\ NYHA $=$ New York Heart Association \\ $\mathrm{TAV}=$ transcatheter aortic valve}

the open aorta after removal of the diseased valve. This study reports the effect of sutureless implantation of the Perceval S bioprosthesis on aortic crossclamp time at implantation, the hemodynamic performance of these valves, and the clinical outcome during early follow-up.

\section{MATERIALS AND METHODS \\ Device and Implantation Technique}

The Perceval S bioprosthesis is constructed from bovine pericardium and is a modification of the Sorin Pericarbon valve (Sorin Biomedica Cardio Srl). The valve is mounted in a Nitinol stent (Figure 1). This stent-mounted valve can be compressed and positioned in a valve delivery system. The delivery system loaded with the compressed stent-mounted valve is guided to its correct position by sliding it over three 4/0 Prolene sutures connected to the annulus. These guiding sutures are stitched through the annulus, halfway between 2 commissures. They are removed after placement of the valve. Once the delivery system is in position, the stent is deployed by turning the release screw and leaving the valve in place. The delivery system and the guiding sutures are removed. Then a balloon is inserted in the valve and expanded during 30 seconds at a pressure of approximately $3 \mathrm{~atm}$. After visual control of the valve position and the coronary ostia, the aorta is closed. Only valves of 2 sizes, nominal labels 21 and 23 , covering annulus diameters ranging from 19 to $21 \mathrm{~mm}$ and 21 to $23 \mathrm{~mm}$, respectively, were available at the time of the study.

\section{Surgical Procedure}

After a median full sternotomy (one case with partial upper sternotomy), the patients were placed on cardiopulmonary bypass (CPB), cannulating the ascending aorta and right atrium. The heart was vented through the right upper pulmonary vein. When coronary bypass surgery was needed, cooling was performed to $32^{\circ} \mathrm{C}$ and the grafts were implanted using intermittent aortic crossclamping. When vein grafts were used, the proximal anastomosis was performed using tangential aortic clamping after completion of the distal anastomoses (during reperfusion) and before the aortotomy. Care was taken to implant the proximal grafts distal from the sinotubular junction to avoid interference with the valve-stent. When the distal (and proximal) anastomoses were complete, the aorta was again crossclamped, retrograde cold-blood cardioplegia was started, and a transverse aortotomy was performed above the sinotubular junction (slightly higher than for a conventional valve given the height of the stent). The diseased valve was completely removed, the annulus was sized, and the sutureless device was implanted as described above. The aortotomy was closed, and the clamp was removed. A case of isolated aortic valve replacement is shown in Video 1.

\section{Patients}

Thirty-two patients entered the study between September 2007 and November 2009. Inclusion criteria were aortic valve stenosis; age more than 75 years; euroSCORE greater than 5 ; and candidate for a standard surgical intervention with a biological prosthesis, an NYHA function class of III or greater, and a small and calcified aortic root/annulus. Exclusion criteria were multivalve lesion, dilatation/dissection of the ascending aorta, previous cardiac surgery, and an aortic valve annulus diameter less than $19 \mathrm{~mm}$

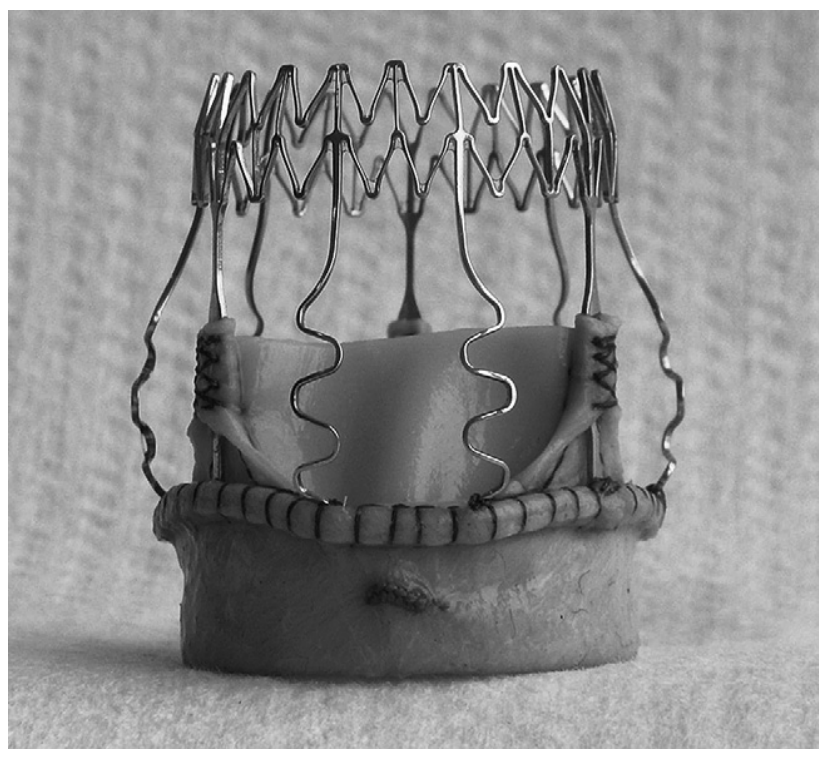

FIGURE 1. Perceval S sutureless bioprosthesis (Sorin Biomedica Cardio Srl, Sallugia, Italy).

or greater than $23 \mathrm{~mm}$ by direct intraoperative measurement. The study was approved by the ethics committee of the hospital. All patients gave written informed consent. Detailed patient characteristics are listed in Table 1.

Postoperatively, all patients were given aspirin only, with a prophylactic dose of low-molecular-weight heparin during hospitalization. Patients in chronic atrial fibrillation were anticoagulated.

\section{Follow-up}

All patients underwent transthoracic echocardiography at discharge and at 6 months and 12 months postoperatively, together with a complete physical examination, electrocardiography registration, and blood sampling. Echocardiography included the measurement of peak and mean transvalvular gradients and effective orifice area. Regurgitation was visualized by color Doppler and scored as $0=$ non-existing, $1=$ trivial, $2=$ mild, $3=$ moderate, or $4=$ severe.

\section{Statistical Analysis}

Data are expressed as mean \pm standard deviation or as proportions where needed. In Tables 1 to 3 , additional information is provided with medians and ranges (given the small patient number). For the analysis of blood element analysis over time, a linear mixed model was used with time points as repeated measurements and patients as subjects.

\section{RESULTS Intraoperative Findings}

In all patients, the surgical procedure went well. Fifty percent of the patients received coronary artery bypass grafting (CABG). The average number of grafts was 2.1 per patient (range, 1-4). As described above, the distal anastomoses were made first using intermittent aortic crossclamping at $32^{\circ} \mathrm{C}$. Thereafter, the aorta was crossclamped for the sutureless placement of the valve. Mean duration of aortic crossclamping needed for the AVR was $17.8 \pm$ 6.2 minutes (median, 17 minutes). Mean total aortic crossclamp time, including the intermittent phases needed to 
TABLE 1. Patient characteristics $(n=32$, median values and range; proportions)

\begin{tabular}{|c|c|}
\hline No. of patients & 32 (female, $65 \%$ ) \\
\hline Age & $78(75-87)$ \\
\hline euroSCORE (median) & $9.99(6.2-34.7)$ \\
\hline STS score (median) & $4.2(1.8-25.8)$ \\
\hline BSA & $1.7(1.3-2.0)$ \\
\hline \multicolumn{2}{|l|}{ Transaortic valve gradient } \\
\hline Mean & $40(15-89)$ \\
\hline Peak & $75(31-137)$ \\
\hline \multicolumn{2}{|l|}{ NYHA class } \\
\hline III & $31 / 32$ \\
\hline IV & $1 / 32$ \\
\hline \multicolumn{2}{|l|}{ Risk factors } \\
\hline Hypertension & $19 / 32$ \\
\hline Smoking & $8 / 32$ \\
\hline Diabetes & $7 / 32$ \\
\hline Dyslipidemia & $16 / 32$ \\
\hline Renal failure & $4 / 32$ \\
\hline Chronic lung disease & $4 / 32$ \\
\hline Previous stroke/TIA & $3 / 32$ \\
\hline Unstable angina & $5 / 32$ \\
\hline $\mathrm{EF}$ & $64(40-84)$ \\
\hline \multicolumn{2}{|l|}{ Rhythm preoperatively } \\
\hline Sinus rhythm & $28 / 32$ \\
\hline Atrial fibrillation & $1 / 32$ \\
\hline Pacemaker & $3 / 32$ \\
\hline \multicolumn{2}{|c|}{ Antithrombotic therapy preoperatively } \\
\hline None & $5 / 32$ \\
\hline Antiplatelets & $24 / 32$ \\
\hline Warfarin & $3 / 32$ \\
\hline
\end{tabular}

$\overline{S T S \text {, Society of Thoracic Surgeons; } B S A \text {, body surface area; } N Y H A \text {, New York Heart }}$ Association; TIA, transient ischemic attack; $E F$, ejection fraction.

perform the distal CABG anastomoses, was $23.4 \pm 10.4$ minutes (median, 22 minutes), and mean CPB time was $54.2 \pm 25.4$ minutes (median, 46 minutes) (Table 2). Weaning from CPB was uneventful in all patients.

\section{Valve Hemodynamics}

Before discharge (ie, $\sim 1$ week to 10 days postoperatively), all patients underwent transthoracic echocardiography. All valves functioned well, peak gradient was $23 \mathrm{~mm}$ $\mathrm{Hg}$, mean gradient was $12 \mathrm{~mm} \mathrm{Hg}$, and effective orifice area was $1.5 \mathrm{~cm}^{2}$ (Table 3). The valves showed absent to trivial (score, $0-1$ ) paravalvular regurgitations in 27 of 32 patients and mild (score, 2) paravalvular regurgitation in 5 of 32 patients. Valvular regurgitation was absent to trivial (score, $0-1$ ) in 25 of 32 patients and mild (score, 2) in 7 of 32 patients. Table 3 summarizes all data, including medians and ranges.

During follow-up (ie, at the 6-month and 1-year echocardiographic examinations), the gradients and effective orifice area values remained stable and there was a tendency in the regurgitation scores to shift from mild to absenttrivial, except in 1 patient, in whom endocarditis with severe
TABLE 2. Intraoperative data (median values and range; proportions)

\begin{tabular}{lc}
\hline \multicolumn{1}{c}{ Transesophageal measurements (mm) } \\
\hline Annulus & $22(18-25)$ \\
Sinus of Valsalva & $33(21-36)$ \\
Sinotubular junction & $27(19-32)$ \\
Size of Perceval S valve (Sorin Biomedica Cardio & \\
$\quad$ Srl, Sallugia, Italy) used & $7 / 32$ \\
$21 \mathrm{~mm}$ & $25 / 32$ \\
$23 \mathrm{~mm}$ & \\
Aortic crossclamp time (min) & $17(12-34)$ \\
$\quad$ For AVR & $22(17-51)$ \\
$\quad$ Total aortic crossclamp time, including intermittent \\
$\quad$ clamping for CABG \\
CPB time (min) \\
$\quad$ Isolated AVR & $46(24-120)$ \\
$\quad$ AVR + CABG & $35(24-54)$ \\
CABG, Coronary artery bypass grafting; $C P B$, cardiopulmonary bypass; $A V R$, aortic \\
valve replacement.
\end{tabular}

(score, 3/4) and valvular and paravalvular regurgitation developed. This patient successfully underwent reoperation. All results are summarized in Table 3.

\section{Blood Analyses}

Blood element analysis showed changes with time after surgery (Table 4). At discharge, red blood cell count hematocrit, hemoglobin, and creatine kinase-MB were significantly lower and white blood cell count was higher than before surgery, but all these parameters recovered completely within the next months. At discharge, the values of free plasma hemoglobin, haptoglobin, reticulocytes, and platelets were not significantly different from those before surgery $(P>.05)$. Serum lactate dehydrogenase, on the other hand, was elevated $(P<.001)$. At 6 and 12 months postoperatively, platelet count and haptoglobin decreased

TABLE 3. Echocardiographic data at follow-up (median values and range; proportions)

\begin{tabular}{lccc}
\hline & $\begin{array}{c}\text { At discharge } \\
(\mathbf{n}=\mathbf{3 2})\end{array}$ & $\begin{array}{c}\mathbf{6} \text { mo } \\
(\mathbf{n}=\mathbf{3 1})\end{array}$ & $\begin{array}{c}\mathbf{1 2} \mathbf{~ m o} \\
(\mathbf{n}=\mathbf{2 5})\end{array}$ \\
\hline Peak pressure gradient & $22(9-50)$ & $18(4-47)$ & $19(5-36)$ \\
Mean pressure gradient & $11(5-28)$ & $10(6-28)$ & $9(3-21)$ \\
Effective orifice area & $1.5(0.8-2.2)$ & $1.2(0.8-2.2)$ & $1.3(0.8-2.4)$ \\
Valvular regurgitation grade & & & \\
$\quad$ Absent-trivial & $25 / 32$ & $25 / 31$ & $21 / 25$ \\
Mild & $7 / 32$ & $5 / 31$ & $4 / 25$ \\
Moderate & 0 & $1 / 31^{*}$ & 0 \\
Severe & 0 & 0 & 0 \\
Paravalvular regurgitation & & & \\
grade & & & \\
Absent-trivial & $27 / 32$ & $25 / 31$ & $23 / 25$ \\
Mild & $5 / 32$ & $5 / 31$ & $2 / 25$ \\
Moderate & 0 & $1 / 31^{*}$ & 0 \\
Severe & 0 & 0 & 0 \\
\hline
\end{tabular}

*One patient with acute bacterial endocarditis. 
TABLE 4. Blood value analysis (mean \pm SD)

\begin{tabular}{|c|c|c|c|c|c|}
\hline & $\begin{array}{l}\text { Preoperative } \\
\quad(\mathbf{n}=\mathbf{3 2})\end{array}$ & $\begin{array}{c}\text { At discharge } \\
\quad(n=32)\end{array}$ & $\begin{array}{c}6 \text { mo } \\
(n=29)\end{array}$ & $\begin{array}{c}12 \text { mo } \\
(n=22)\end{array}$ & Time effect \\
\hline Red blood cells $\left(10^{12} / \mathrm{L}\right)$ & $4.11 \pm 0.53$ & $3.57 \pm 0.38 *$ & $4.22 \pm 0.81$ & $4.16 \pm 0.42$ & $P<.001$ \\
\hline White blood cells $\left(10^{9} / \mathrm{L}\right)$ & $8.18 \pm 4.43$ & $9.89 \pm 5.11 \ddagger$ & $7.81 \pm 4.48$ & $6.57 \pm 2.30$ & $P=.015$ \\
\hline Hematocrit & $37.8 \pm 4.7$ & $33.2 \pm 3.6^{*}$ & $37.5 \pm 4.3$ & $38.5 \pm 3.7$ & $P<.001$ \\
\hline Hemoglobin (g/dL) & $12.1 \pm 1.7$ & $10.5 \pm 1.0^{*}$ & $11.8 \pm 1.4$ & $12.7 \pm 1.8$ & $P<.001$ \\
\hline Free plasma hemoglobin (mg/dL) & $3.4 \pm 3.8$ & $2.7 \pm 4.5$ & $5.5 \pm 4.6$ & $5.2 \pm 4.7$ & $P=\mathrm{NS}$ \\
\hline Haptoglobin (g/L) & $2.1 \pm 2.1$ & $1.8 \pm 1.0$ & $0.9 \pm 0.8 \S$ & $0.9 \pm 0.6 \oint$ & $P<.001$ \\
\hline Reticulocytes $\left(10^{9} / \mathrm{L}\right)$ & $4.20 \pm 5.17$ & $7.62 \pm 8.14$ & $15.04 \pm 19.93 \dagger$ & $11.86 \pm 15.52 \dagger$ & $P=.007$ \\
\hline Platelets $\left(10^{9} / \mathrm{L}\right)$ & $241 \pm 61$ & $249 \pm 127$ & $175 \pm 64 \S$ & $184 \pm 57 \S$ & $P<.001$ \\
\hline Serum LDH (U/L) & $428 \pm 113$ & $747 \pm 205 \dagger$ & $590 \pm 149 \S$ & $584 \pm 194 \S$ & $P<.001$ \\
\hline CK-MB $(\mu \mathrm{g} / \mathrm{L})$ & $1.67 \pm 1.42$ & $1.00 \pm 0.49 *$ & $1.68 \pm 1.10$ & $1.55 \pm 1.40$ & $P=.004$ \\
\hline
\end{tabular}

$L D H$, Lactate dehydrogenase; $C K-M B$, creatine kinase-MB; $N S$, not significant. *Different from all other time points. $\dagger$ Different from preoperative value. $\ddagger$ Different from

12 -month value. $§$ Different from preoperative and discharge values.

$(P<.001)$, and reticulocytes and serum lactate dehydrogenase were elevated $(P<.001)$. The decrease in platelet count was moderate and not observed in all patients: Eight patients $(25 \%)$ had platelet counts more than $20010^{9} / \mathrm{L}$; none of the patients had counts less than $10010^{9} / \mathrm{L}$. All results from the blood analyses over time are listed in Table 4 .

\section{Clinical Outcome}

Median follow-up duration was 15.8 months. One patient ( $3 \%$ ) required surgical revision for bleeding, and 4 patients $(12 \%)$ required pleural puncture for pleural effusion. Mean hospital stay was 15 days (range, 4-30 days). Median intensive care unit stay was 2 days. One patient required temporary renal dialysis during the intensive care unit stay. All 32 patients went home or were admitted to a rehabilitation center in good condition. Between 6 and 12 months postoperatively, there were 3 deaths ( 2 with respiratory failure after infection, 1 after gastrointestinal bleeding). Acute bacterial endocarditis developed in 1 patient, who successfully underwent reoperation after 6 months. In all patients except 1 , cardiac rhythm remained essentially unaltered after the sutureless valve replacement. A previously non-existing atrioventricular block developed in 1 patient, who received a permanent pacemaker implantation. None of the patients experienced a thromboembolic or bleeding event during follow-up. New York Heart Association (NYHA) function class improved. Preoperatively, $97 \%$ of patients were in NYHA class III and $3 \%$ of patients were in NYHA class IV (Table 1). At 6 months postoperatively, $35 \%$ of patients were in NYHA class I, $62 \%$ of patients were in NYHA class II, and $3 \%$ of patients were in NYHA class III. At 1 year, $48 \%$ of patients were in NYHA class I, $48 \%$ of patients were in NYHA class II, and $3 \%$ of patients were in NYHA class III.

\section{DISCUSSION}

For symptomatic patients with severe aortic valve stenosis, open surgery for AVR with the use of cardioplegic arrest under CPB remains the golden standard. The actual tech- nique carries an (unacceptably) high perioperative risk only in elderly patients with multiple comorbidities. For these patients, TAV procedures were developed on a compassionate basis. ${ }^{4,5}$ Currently, TAV procedures have lost their compassionate basis, and inoperable and "high-risk" candidates are recruited. TAV procedures still carry the risk of several periprocedural complications that may be lifethreatening. ${ }^{1}$ Dislocation or embolization of the graft, aortic rupture and dissection, and obstruction of coronary ostia are all devastating complications. The majority of patients will have perivalvular insufficiency after TAV, and the incidence of atrioventricular block is high. ${ }^{1}$ The retrograde approach via the femoral artery is associated with several vascular complications. The antegrade transapical approach requires intubation and thoracotomy with the risk of bleeding from the apex of the heart. ${ }^{6}$ These possible complications of the TAV technology justify the search for an alternative technique to safely replace the aortic valve in high-risk candidates for open surgery. We know from previous studies that the duration of aortic crossclamping and CPB are independent predictors of survival after valve replacement and combined valve operations with $\mathrm{CABG}{ }^{7}$ Therefore, a technology focused on shortening aortic crossclamp time and consequently CPB time is mandatory. The sutureless implantation technique, as implemented with the Perceval S aortic valve, has the potential of shortening aortic crossclamp time. Our results show that it is possible to implant a well-functioning sutureless stent-mounted valve in the aortic position in less than 20 minutes of aortic crossclamping, including complete removal of the diseased native valve without jeopardizing valve function. The decalcification that we performed is similar to what is done for other valves. There is no need to be more aggressive or to leave calcium in place.

Our study was not designed to prove the superiority of a sutureless implantation over any other technique, such as TAV or classic open AVR. We only describe the results in terms of mortality, morbidity, and valve hemodynamics. Operative mortality in our limited series of sutureless aortic 
valve implants was $0 \%$. Despite their high-risk profile and advanced age, all patients recovered from surgery. Perioperative morbidity was low. Low cardiac output syndrome during the postoperative phase or signs of renal failure did not develop in any patient. Vascular complications did not develop in any patient. On the basis of echocardiographic measurements, short-term efficacy and hemodynamics of the Perceval S bioprosthesis are good. However, to reliably evaluate long-term outcomes of this bioprosthesis, followup studies longer than 1 year are needed. Our finding of a moderate decrease in platelet count at 6 and 12 months postprocedure particularly requires closer investigation. It is known that many artificial heart valves, mainly the mechanical variants, induce some degree of hemolysis without leading to serious clinical problems. In some cases, severe paravalvular leakage can give rise to more relevant hemolysis. Although we did not observe moderate to severe paravalvular or valvular regurgitation in our patients (except for 1 patient in whom endocarditis developed), this mechanism cannot be excluded in our series of Perceval $\mathrm{S}$ valves to explain the long-lasting effects on blood element integrity. We looked for a possible correlation between the decrease of platelets and the occurrence of paravalvular leaks or to valve size, but neither seemed to be correlated in this small cohort of patients. Also, it is known that other stentless but not sutureless bioprostheses, such as the Solo valve (Sorin Biomedica Cardio Srl), can induce thrombocytopenia in the first postoperative days. ${ }^{8}$ The mechanism has never been elucidated, and, as in our actual study of the Perceval $\mathrm{S}$ valve, the phenomenon has no detectable clinical relevance.

The Perceval $\mathrm{S}$ is not the only sutureless valve design currently under investigation. Other types of sutureless valves have been implanted clinically. ${ }^{9-11}$ However, mean aortic crossclamp times in these studies were $39 \pm 15$ minutes, ${ }^{9}$ $55 \pm 11$ minutes, ${ }^{10}$ and $70 \pm 23$ minutes, ${ }^{11}$ all significantly longer than the crossclamp times in our experience with Perceval S. The durability of these sutureless valves is another issue. None of the currently available transfemoral or transapical heart valves have proven durability. These implant procedures are still limited to a special population of elderly and ill patients. Although it is known that bioprosthesis durability is better in older patients, durability studies are still mandatory. It will be tempting to extend the use of the Perceval S valve to the entire population of patients requiring a bioprosthesis in the aortic position.

\section{CONCLUSIONS}

The Perceval $\mathrm{S}$ valve is an efficient and well-functioning device that offers the advantage of considerably shortening the duration of aortic crossclamping. Whether this will affect mortality and morbidity substantially in elderly patients is debatable. One major advantage of this valve will be seen in patients undergoing complex operations, such as concomitant mitral/tricuspid surgery and coronary revascularization, especially in compromised ventricles. Adequate follow-up studies are required to reliably evaluate longterm outcome.

\section{References}

1. Yan TD, Cao C, Martens-Nielsen J, Padang R, Ng M, Vallely MP, et al. Transcatheter aortic valve implantation for high-risk patients with severe aortic stenosis: a systematic review. J Thorac Cardiovasc Surg. 2010;139: 1519-28.

2. Vahanian A, Alfieri OR, Al-Attar N, Antunes MJ, Bax J, Cormier B, et al. Transcatheter valve implantation for patients with aortic stenosis: a position statement from the European Association of Cardio-Thoracic Surgery (EACTS) and the European Society of Cardiology (ESC), in collaboration with the European Association of Percutaneous Cardiovascular Interventions (EAPCI). Eur J Cardiothorac Surg. 2008;34:1-8.

3. Shrestha M, Folliguet T, Meuris B, Dibie A, Bara C, Herregods MC, et al. Sutureless Perceval S aortic valve replacement: a multicenter, prospective pilot trial. J Heart Valve Dis. 2009;18:698-702.

4. Webb JG, Pasupati S, Humphries K, Thompson C, Altwegg L, Moss R, et al. Percutaneous transarterial aortic valve replacement in selected high-risk patients with aortic stenosis. Circulation. 2007;116:755-63.

5. Cribier A, Eltchaninoff H, Bash A, Borenstein N, Tron C, Bauer F, et al. Percutaneous transcatheter implantation of an aortic valve prosthesis for calcific aortic stenosis: first human case description. Circulation. 2002;106:3006-8.

6. Kallenbach K, Karck M. Percutaneous aortic valve implantation. Herz. 2009;34: 130-9.

7. Flameng WJ, Herijgers P, Szécsi J, Sergeant PT, Daenen WJ, Scheys I. Determinants of early and late results of combined valve operations and coronary artery bypass grafting. Ann Thorac Surg. 1996;61:621-8.

8. Piccardo A, Rusinaru D, Petitprez B, Marticho P, Vaida I, Tribouilloy C, et al. Thrombocytopenia after aortic valve replacement with Freedom Solo bioprosthesis: a propensity study. Ann Thorac Surg. 2010;89:1425-30.

9. Breitenbach I, Wimmer-Greinecker G, Bockeria LA, Sadowski J, Schmitz C, Kapelak B, et al. Sutureless aortic valve replacement with the Trilogy Aortic Valve System: multicenter experience. J Thorac Cardiovasc Surg. 2010;140 878-84, 884.e1. Epub 2010 Aug 2.

10. Aymard T, Kadner A, Walpoth N, Göber V, Englberger L, Stalder M, et al. Clinical experience with the second-generation 3 f Enable sutureless aortic valve prosthesis. J Thorac Cardiovasc Surg. 2010;140:313-6.

11. Martens S, Ploss A, Sirat S, Miskovic A, Moritz A, Doss M. Sutureless aortic valve replacement with the 3 f Enable aortic bioprosthesis. Ann Thorac Surg. 2009;87:1914-7. 